\title{
LABORATORY TRAILS TO EVALUATE THE PREDATORY MITE Neoseiulus cucumeris ( OUDEMAN ) WHEN FED ON EUROPEAN RED MITE Panonychus ulmi ( KOCH ) UNDER DIFFERENT DEGREES OF TEMPERATURES \\ Mohamed, K.E.; N.M. Abd-EI-Wahed and Mona S. El Ghobashy \\ Plant Protection Res. Inst. Agric. Res. Center, Dokki , Giza, Egypt .
}

\begin{abstract}
Biological aspects of the predatory mite Neoseiulus cucumeris (Oud.) was investigated in the Laboratory at 20,25 and $30 \mathrm{C} \cdot$ and $65 \pm 5 \% \mathrm{R}$. $\mathrm{H}$ To evaluate the efficieny of the predatory mite, when fed on movable stages of european red mite, Panonychus ulmi (Koch) in Egypt. The incubation period lasted (4.31\&4.0), (3.6\&3.2) and (2.6\&2.3) days for female and male at 20,25 and 30 C., respectively. Total immature stages for female averaged $8.85 \pm 0.29 ; 5.7 \pm 0.42$ and ; $4.6 \pm 0.51$ days while for male averaged $8.15 \pm 0.49 ; 5.25 \pm 0.34$ and $4.1 \pm 0.64$ days at 20,25 and $30 \mathrm{C} \circ$ respectively. Female longevity was longer than male, this period averaged (26.65 \& 18.2), (20.15\& 14.7$)$ and (18.8 \& 13.1) days at 20,25 and 30 respectively Trials on predation showed that, female fed on greater number of prey individuals than male . During life span , female consumed $59.23 \pm 2.03,92.27 \pm 2.14$ and 74.73 \pm 1.58 prey of $P$. ulmi, respectively at the previous temperature while male consumed $39.78 \pm 1.82,65.23 \pm 2.50$ and $47.69 \pm 1.94$ prey respectively at 2025 and $30 \mathrm{C}^{\circ}$
\end{abstract}

\section{INTRODUCTION}

Mites of the family phytoseiiedae are receiving more attention because of their role as predators of phytophagous mites and other small insect. The predacious mite, Neoseiulus cucumeris (Oud.) used as abiocontrol agent for suppressing mites and thrips popualtion by Bieri et al. (1989), Marisa and Saure (1990), Tuovinen et al. (2002), Li et al. (2003), and Ibrahim et al. (2005).

The predatory mite $N$. cucumeris import from Holland to use in biological control.

The present study aims to throw some light on the biological aspects of predatory mite $N$. cucumeris when fed on the european red mite $P$. ulmi at 20,25 and $30 \mathrm{C}$ and $65 \pm 5 \mathrm{R} \mathrm{H}$.

\section{MATERIALS AND METHODS}

The predatory mite Neoseiulus cucumeris (Oud.) was reared on apple leaf discs of about $3 \mathrm{~cm}$ in diameters. These discs were placed on soaked cotton wool in Petri-dishes, water was daily added to maintain suitable moisture for the predator development . Individuals of $N$. cucumeris were fed singly during their life span on the movable stages of Pananychus ulmi ( Koch).

The biologiacl aspects of the predatory mite were noticed and recorded the number of devoured individuals of the prey were counted and then replaced by another alive one until the end of life span. Experiments were carried out under laboratory conditions of $20,25 \& 30 \mathrm{C}$ and $65 \pm 5$ $\%$ R. H. 


\section{RESULTS AND DISCUSSION}

Duration of development stages of $N$. cucumeris as shown in table (1), the incubation period of female and male averaged (4.31 \& 4.0$),(3.6 \&$ 3.2 ) and 2.6 \&2.3) days at 20,25 and $30 \mathrm{C}$. respectively . Female larva stayed $1.95,1.1$ and 0.8 days , while the male larva dratted $1.84,0.92$ and 0.7 days at 20,25 and 30 Co respectively. The protonymphal stages lasted $3.12 \pm 0.20 ; 2.2 \pm 0.42$ and $1.8 \pm 0.37$ days and $2.81 \pm 0.23 ; 2.1 \pm 0.49$ and $1.5 \pm 0.43$ days for female and male at 20,25 and $30 \mathrm{C}$; , respectively , while the deutonymphal stage durated $3.78 \pm .55 ; 2.4 \pm 0.27$ and $2.00 \pm 0.33$ days and $3.5 \pm 0.36 ; 2.2 \pm 0.26$ and $1.8 \pm 0.25$ days for female and male at 20,25 and $30 \mathrm{C} \dot{\circ}$, respectively .

Also data in table (1) showed that the female total immature stages lasted $8.89 \pm ; 5.8 \pm 0.42$ and $4.6 \pm 0.51$ days while that for male lasted $8.15 \pm$ $0.49 ; 5.25 \pm 0.34$ and $4.1 \pm 0.64$ days at the perevious temperature respectively. The life cycle of female and male durated (13.61 \& 12.15 ), (9.3 \&8.42) and ( 7.2 \& 6.3 ) days at the same trend. Female life cycle was longer than male. Male adulthood was shorter than female longevity, this period averaged ( 18.2 \& 26.65$),(14.7 \& 20.15$ and $(13.1 \& 18.8)$ days at the same pottern. The female and male life span averaged $39.89 \pm 0.46$; $30.4 \pm 1.05$ days at $20 \mathrm{C}$ while at $25 \mathrm{C}$ ' averaged $29.5 \pm 1.65 ; 23.5 \pm 1.48$ days, but lasted $26.2 \pm 1.96 ; 19.6 \pm 1.68$ days at $30 \mathrm{C}$,.

Table (1): Influence of temperature on life cycle and longevity of Neoseiulus cucumeris (Oud.) when fed on movable stages of Panonychus ulmi (Koch) at 20,25\&30 Cं and $65 \pm 5$ R.H.

\begin{tabular}{|c|c|c|c|c|c|c|}
\hline \multirow{3}{*}{$\begin{array}{l}\text { Developmental } \\
\text { stages }\end{array}$} & \multicolumn{6}{|c|}{ Duration ( in days ) } \\
\hline & \multicolumn{2}{|c|}{ Mean \pm S D at $20 \mathrm{C}$} & \multicolumn{2}{|c|}{ Mean \pm S D at $25 \mathrm{C}$} & \multicolumn{2}{|c|}{ Mean \pm S D at $30 \mathrm{C}$} \\
\hline & Female & Male & Female & Male & Female & Male \\
\hline Egg & $4.31 \pm 0.64$ & $4.00 \pm 0.22$ & $3.6 \pm 0.76$ & $3.2 \pm 0.26$ & $2.6 \pm 0.39$ & $2.3 \pm 0.26$ \\
\hline Larva & $1.95 \pm 0.28$ & $1.84 \pm 0.24$ & $1.1 \pm 0.41$ & $0.92 \pm 0.12$ & $0.8 \pm 0.19$ & $0.7 \pm 0.19$ \\
\hline Protonymph & $3.12 \pm 0.20$ & $2.81 \pm 0.23$ & $2.2 \pm 0.42$ & $2.1 \pm 0.49$ & $1.8 \pm 0.37$ & $1.5 \pm 0.43$ \\
\hline Deutonymph & $3.78 \pm 0.55$ & $3.5 \pm 0.36$ & $2.4 \pm 0.27$ & $2.2 \pm 2.26$ & $2.00 \pm 0.33$ & $1.8 \pm 0.25$ \\
\hline Total immature & $8.85 \pm 0.29$ & $8.15 \pm 0.49$ & $5.7 \pm 0.42$ & $5.22 \pm 0.34$ & $4.6 \pm 0.51$ & $4.0 \pm 0.64$ \\
\hline Lifer cycle & $13.16 \pm 0.34$ & $12.15 \pm 0.35$ & $9.3 \pm 0.44$ & $8.42 \pm 0.47$ & $7.2 \pm 0.71$ & $6.3 \pm 0.64$ \\
\hline Longevity & $26.65 \pm 0.45$ & $18.2 \pm 1.79$ & $20.15 \pm 1.49$ & $14.7 \pm 1.43$ & $18.8 \pm 2.11$ & $13.1 \pm 1.51$ \\
\hline Life span & $39.8 \pm 0.46$ & $30.3 \pm 1.05$ & $29.5 \pm 1.65$ & $23.1 \pm 1.48$ & $26.3 \pm 1.96$ & $19.4 \pm 1.68$ \\
\hline
\end{tabular}

The data showed that the predator life span period at $20 \mathrm{C}:$ was longest than 25 and $30 \mathrm{C}^{\circ}$, the duration of male was shoter than female Abd El-Wahed. ( 2007 )

Data in table (2) demonstrated that the pre-ovoposition period lasted $2.5 \pm 0.41 ; 1.5 \pm 0.43$ and $1.6 \pm 0.40$ days at $20 ; 25$ and $30 \mathrm{C}$ respectively. the oviposition period of female predator dratted $21.53 \pm 0.43 ; 16.3 \pm 1.56$ and $15.00 \pm 2.12$ days at the previous temperature, respectively, while the post-oviposition period averaged $2.62 \pm 0.34 ; 2.35 \pm 0.46$ and $2.1 \pm 0.35$ days at the same trend. Females deposited an average of $23.6,24.0$ and 18.0 eggs with a daily rate of $1.1 \pm 08 ; 1.5 \pm 0.22$ and $1.2 \pm 0.21$ eggs at 20 ; 25 and $30 \mathrm{C}$ respectively . 
Table (2): Effect of temperatures on the fecundity and longevity $N$. Cucumeris females when fed on movable stages of $P$.ulmi.

\begin{tabular}{|l|c|c|c|c|c|c|}
\hline \multirow{2}{*}{ Tempereture } & \multicolumn{3}{|c|}{ Average Period in days } & No . of eggs / female \\
\cline { 2 - 7 } & $\begin{array}{c}\text { Pre } \\
\text { oviposition }\end{array}$ & Oviposition & $\begin{array}{c}\text { Post - } \\
\text { oviposition }\end{array}$ & Longevity & Total & Daily rate \\
\hline $\mathbf{2 0 ~ C} \cdot$ & $2.5 \pm 0.41$ & $21.53 \pm 0.43$ & $2.62 \pm 0.34$ & $26.65 \pm 0.54$ & $23.6 \pm 1.36$ & $1.1 \pm 0.8$ \\
\hline $\mathbf{2 5} \mathbf{C}$ & $1.5 \pm 0.43$ & $16.3 \pm 1.56$ & $2.35 \pm 0.46$ & $20.15 \pm 1.49$ & $24.0 \pm 2.46$ & $1.5 \pm 0.22$ \\
\hline $\mathbf{3 0} \mathbf{C}$ & $1.6 \pm 0.40$ & $15.00 \pm 2.12$ & $2.1 \pm 0.35$ & $18.8 \pm 2.11$ & $18.0 \pm 2.22$ & $1.2 \pm 0.21$ \\
\hline
\end{tabular}

prey consumed by different stages of $\boldsymbol{N}$. cucumeris when fed on different stages of $P$ umli at $20,25 \& 30 \mathrm{C}$ and $65 \pm 5 \%$ R.H.

Data in table (3) demonstrated that the developmental stages of predatory mite. N. cucumeris consumed different movable stages of P.ulm as prey. The average number of consumption of movable stages of $P$. ulmi increased as development of the predator stages .

The average number of prey Consumed prey by $N$. Cucumeris during larvae, protonymph and deutonyph stages were $(0.7,2.4 \& 4.9),(1.1,4.6$ \& $9.5)$ and $(0.9,2.9 \& 5.8)$ while male efficiency was less than female, he destroyed $(0.6,2.2 \& 4.5),(1.0,4.3 \& 8.7)$ and $(0.7,2.5 \& 4.9)$ mite individuals at different degrees of temperature. During total immature stages females fed more than males, the average number of prey consumed were $(8.1 \pm 0.89 ; 7.4 \pm 0.73),(15.25 \pm 0.85 ; 14.14 \pm 0.49)$ and $(9.7 \pm 0.47 ; 8.27$ \pm 0.66 ) mite individuals for female and male at $20 ; 25$ and $30 \mathrm{C} \cdot$ respectively

During the pre-oviposition, oviposition and post- oviposition period , the average number of consumed prey were $6.2 \pm 2.29 ; 38.87 \pm 2.22$ and 5.6 \pm 1.09 individuals at $20 \mathrm{C} ;$; while it average $9.6 \pm 0.47 ; 58.8 \pm 1.89$ and $8.6 \pm$ 0.69 individuals at $25 \mathrm{C} ;$; but at $30 \mathrm{C} \dot{\circ}$ it averaged $8.9 \pm 0.41 ; 49.09 \pm 1.48$ and $7.06 \pm 0.66$ individuals, respectively .

The average number of consumed prey by adult females and males were $51.12 \pm 2.03 ; 32.44 \pm 2.06$ and $77.02 \pm 1.93 ; 48.08 \pm 2.77$ and $65.02 \pm$ $1.61 ; 39.43 \pm 1.60$ individuals at 20,25 and $30 \mathrm{C}$; respectively .

Table (3): Efficiency of Neaseiulus cucumeris (Oud.) in predating on movable stages of $P$. ulmi at different degrees of temperatures.

\begin{tabular}{|c|c|c|c|c|c|c|}
\hline \multirow{3}{*}{$\begin{array}{l}\text { Developmental } \\
\text { stages }\end{array}$} & \multicolumn{6}{|c|}{ Average No . of Consumed prey ( P. ulmi ) } \\
\hline & \multicolumn{2}{|c|}{ Mean \pm S D at $20 \mathrm{C}$} & \multicolumn{2}{|c|}{ Mean \pm S D at $25 \mathrm{C}$} & \multicolumn{2}{|c|}{ Mean \pm S D at $30 \mathrm{C}$} \\
\hline & Female & Male & Female & Male & Female & Male \\
\hline larva & $0.7 \pm 0.14$ & $0.6 \pm 0.20$ & $1.1 \pm 0.23$ & $1.00 \pm 0.25$ & $0.9 \pm 0.29$ & $0.7 \pm 0.33$ \\
\hline protonymph & $2.4 \pm 0.37$ & $2.2 \pm 0.26$ & $4.6 \pm 0.48$ & $4.3 \pm 0.38$ & $2.9 \pm 0.31$ & $2.5 \pm 0.41$ \\
\hline Deutonymph & $4.9 \pm 0.85$ & $4.5 \pm 0.49$ & $9.5 \pm 0.46$ & $8.7 \pm 0.98$ & $5.8 \pm 0.41$ & $4.9 \pm 0.41$ \\
\hline Total immatures & $8.1 \pm 0.89$ & $7.4 \pm 0.73$ & $15.25 \pm 0.85$ & $14.14 \pm 0.49$ & $9.7 \pm 0.47$ & $8.27 \pm 0.66$ \\
\hline Pre- oviposition & $6.2 \pm 2.29$ & & $9.6 \pm 0.47$ & & $8.9 \pm 0.41$ & \\
\hline Oviposition & $38.87 \pm 2.22$ & & $58.8 \pm 1.89$ & & $49.09 \pm 1.48$ & \\
\hline Post - oviposition & $5.6 \pm 1.09$ & & $8.6 \pm 0.69$ & & $7.06 \pm 0.66$ & \\
\hline Longevity & $51.2 \pm 2.03$ & $32.44 \pm 2.06$ & $77.02 \pm 1.93$ & $48.08 \pm 2.27$ & $65.02 \pm 161$ & $39.43 \pm 1.60$ \\
\hline Life span & $59.23 \pm 2.03$ & $39.78 \pm 1.82$ & $92.27 \pm 2.14$ & $65.23 \pm 2.50$ & $74.73 \pm 1.58$ & $47.69 \pm 1.94$ \\
\hline
\end{tabular}

The predater mite $N$. Cucumeris could cosume $59.33 \pm 2.03 ; 39.78 \pm$ 1.82 for females and males at $20 \mathrm{C} \dot{\circ} ; 92.27 \pm 2.14 ; 62.23 \pm 2.50$ individuals 
at $25 \mathrm{C} \dot{\circ}$; while it consumed $74.73 \pm 1.58 ; 47.69 \pm 1.94$ individual at $30 \mathrm{C} \dot{\circ}$ during life span .

Female was more efficiency of destroying prey at $25 \mathrm{C} \dot{\circ}$ than other temperature degrees, she consumed 58.8 prey during ovi positions period with a daily rate 3.6 prey and deposited high number of eggs (24) with a daily rate 1.5 eggs. From the previous results, the predatory mite N. Cucumeris may be considered one of the biological control agents of the european red mite P. ulmi on different crops. Theses results are in agreement with Zhang et al. (2000), Zhang et al. (2001), Blaeser et al. (2002), lin and Huang (2003), Zhang et al. (2003 a), Zhang et al. (2003 b), Ibrahim et al.(2005), Ibrahim et al. ( 2006 ) and Abd El-Wahed ( 2007).

\section{REFERENCES}

Abd El - Wahed N. M . (2007) : Biological studies of predacious mite Neoseiulus Cucumeris (oudman) when fed on citrus red mite , Panonychus citri ( M c Gregor ) . Egypt . J. Agric . Res , 85 (4) , 1253 1258 .

Bieri , M., F. Zwygart, G . Tognina and G. Stadler ( 1989 ) : The importance of soil water content for the biological control of thrips tabaci lin . on Cucumber in the greenhouse. Mitteilungen - der - Schweizerischen Gesellschaft , 62:1- 2 .

Blaeser, P. , I . Lieonart, M. Sitjar and C. Sengonca ( 2002 ) : Laboratory studies on the development, Longevity and reproducation of four Amblyseius predator mites Fed with Tetranychus urticae and Frankliniella occidentalis ( pergande). Nachrichten - des Deutschen Pflanzenschutzdienstes, 54 (12) : $307-311$.

Ibrahim , G. A , A. M . Halawa and N.M . Abd El-Wahed ( 2005) : Biological aspects of predcious mite Neoseiulus Cucumeris (Oud) when fed on postembryonic stages of Tetranychus urticae Koch . Egypt, J. Agric . Res, 83 (4) : $1681-1687$.

Ibrahim , G. A ., N. M . Abd El -wahed and A. M Halawa (2006 ) : Biological control of the two spotted spider mite Tetranychus urticae koch using phytosiied mite, Noeseiulus cucumeris (oudman) on cucumber (Acari : Tetronychidae : Phytoseiidae) Egypt . J. Agric . Res - 84 (4) : $1033-1037$.

Lin , B. S . and J. S . Hung ( 2003 ) : Experiment of using mites to control the mites . South China fruits $32: 1,11$.

Li , J. Y. Y. yang , Q.Y. fang and W. U. Q. Hong (2003) : Experimental population life table of Amblsyseius Cucumeris with polyphagotarsonemus latus prey. Act a -phytophylacica - Sinlea , 30 (4) : $389-395$.

Marisa, C. and . S. Sauro ( 1990$)$ : Biological observations and life table parameters of Amblyseius Cucumeris ( Oud ) (Acarina : Phytoseiidae ) reared on different diets . Redia , 73 ( 2) : 259- 583.

Tuovinen , T. T. Hietaranta , M. M . Limma , P. Palonen and P. parikka (2002): Biological control of strawberry mite a case study . proceedings 
of the fourth International strawberry symbosium tampere, finland, July 9-14 V. 2 Acta - Horticulture , No . 567 ( V. 2 ) : $671-674$.

Zhang, Y. X , J. Z Lin , J.J . A. Hou and Q. Zhang ( 2003 a) : Studied on the life histotory of Amblyseius Cucumeris for control of citrus mite for Navel orange . South china fruits, $32: 1,12-13$.

Zhang , Y. X , J. Z . Lin . J. Ji . A. Hou and q. Zhang ( 2003 b ) : study on using of Amblyseius cucumeris (Acari : Phytoseiidate) feeding on Aponychus corpuzee (Acari : Tetranychildae ) Systematic and applied acarology , $8: 67-74$.

Zhang , Y. X Z. zhang . J. lin and J. Ji ( 2000 ) : potentail of Amblyseius cucumeris (Acari : Phytoseiildae) as a biocontrol agenst Schizotetrenychus manjingensis (Acari Tetranychidae) in Fujian, China . Biology and control of bamboo mites in Fujian. Special publication systematic and applied Acarology , No . 4, $109-124$.

Zhang,Y.X, Z.Q. Zhang, C.P chen, J.Z. lin and X. chen. (2001): Amblyselus cucumeris (Acari: phytoseiidae as abiocotrol agent against Panonychus citri (Acari : Tetranychidae) on citrus in China . Systematic and applied Acarology , $6: 35-44$.

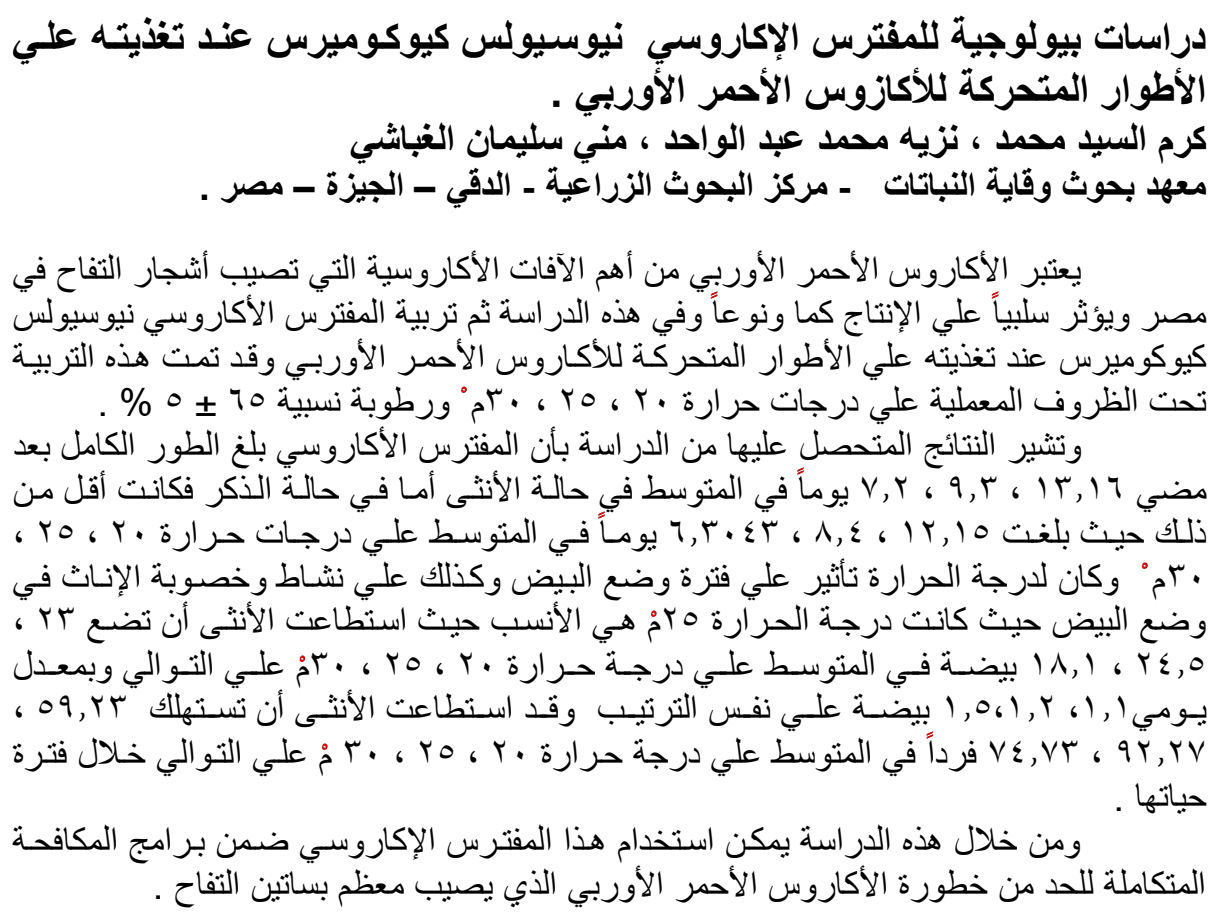

